\title{
LAS TECNOLOGÍAS DE LA INFORMACIÓN Y LAS COMUNICACIONES COMO HERRAMIENTAS PARA LA GESTIÓN DEL PATRIMONIO CULTURAL CON UNA VISIÓN EMPRENDEDORA
}

\author{
C. V. TAMAYO ${ }^{*}$ e E. LEITE ${ }^{2}$ \\ ${ }^{1}$ Universidad de Granma \\ ${ }^{2}$ Universidade de Pernambuco \\ cvaldespinot@udg.co.cu*
}

Manuscrito recibido en noviembre/2015 y aceptado en diciembre/2015

DOI: $10.15628 /$ holos.2015.3660

\section{RESUMEN}

El patrimonio cultural no se limita a monumentos y colecciones de objetos, comprende también tradiciones o expresiones vivas heredadas de nuestros antepasados y transmitidas a nuestros descendientes. La importancia de este recurso inmaterial no radica solo en la manifestación cultural en sí, sino en el cúmulo de conocimientos y técnicas que se transmiten de generación en generación. Se basa en el reconocimiento por las comunidades, grupos o individuos que lo crean, mantienen y transmiten. La difusión es uno de los tres pilares de la gestión del patrimonio. Su definición merece una revisión a la luz de nuevas disciplinas y estrategias de comunicación incorporadas en los últimos diez años. El espíritu empresarial y la visión emprendedora junto al desarrollo tecnológico, están generando un profundo impacto en todos los ámbitos de la vida diaria, desencadenando aspectos positivos en la gestión y
\end{abstract}

conservación del patrimonio cultural. En la presente investigación se da a conocer el papel que han desempeñado las Tecnologías de la Información y las Comunicaciones, como herramienta insustituible, en la difusión del patrimonio, partiendo de una mirada emprendedora. Se describe el aporte de tres de las principales líneas de desarrollo de software a este pilar fundamental (Realidad Virtual, Sistemas de Información Geográfica y Portales WEB), las herramientas y tecnologías más utilizadas en estas ramas, así como los sistemas informáticos desarrollados a partir de investigaciones científicas realizadas en la Carrera de Ingeniería en Ciencias Informáticas de la Universidad de Granma, como resultado de un trabajo intencionado realizado con la dirección de Patrimonio y Cultura en la provincia.

PALABRAS CLAVE: patrimonio cultural, difusión, Tecnología de la Información y las Comunicaciones, visión emprendedora

\section{THE INFORMATION TECHNOLOGY AND COMMUNICATIONS AS TOOLS FOR CULTURAL HERITAGE MANAGEMENT WITH AN ENTREPRENEURIAL VISION.}

\section{ABSTRACT}

Cultural heritage is not limited to monuments and collections of objects, also includes traditions or living expressions inherited from our ancestors and passed on to our descendants. The importance of this intangible resource lies not only in the cultural manifestation itself but in the body of knowledge and techniques passed down from generation to generation. It is based on the recognition by the communities, groups or individuals that create maintain and transmit. Diffusion is one of the three pillars of asset management. Its definition deserves a review in the light of new disciplines and communication strategies built in the last ten years. Sustainable technological development is creating a profound impact on all areas of daily life, triggering positive aspects in the management and
\end{abstract}

conservation of cultural heritage. Entrepreneurship and entrepreneurial vision with technological development are generating a profound impact on all areas of daily life, triggering positive aspects in the management and conservation of cultural heritage. The contribution of three main lines of development of software to this fundamental pillar (Virtual Reality, GIS and web portals), tools and technologies most commonly used in these industries, as well as informatics systems developed from scientific research in the engineering degree in computer science of the University of Granma, as a result of an intentional work with management of Heritage and Culture in the province.

KEYWORDS: cultural heritage , broadcasting, Information Technology and Communications, entrepreneurial vision 


\section{INTRODUCCIÓN}

En las últimas décadas del siglo XX e inicios del XXI, el patrimonio cultural se ha enriquecido con nuevas categorías y concepciones. El patrimonio continúa su desarrollo con un enfoque global, antropológico, etnográfico y sociológico, que establecen disímiles manifestaciones con características particulares de su época e historia. En estos tiempos de creciente globalización; la protección, conservación, y presentación de la diversidad patrimonial de cualquier sitio o región es un importante desafío para la sociedad.

Es innegable que los centros históricos y culturales son parte relevante del patrimonio de las ciudades, contenedores identitarios de sus bienes, que transmiten en su estructura urbana la expresión más antigua procedente del pasado. Por la aglomeración monumental contienen un indiscutible valor cultural, social, urbanístico, arquitectónico, ecológico y simbólico. El enfoque en la gestión pública requiere de la incorporación de una visión empresarial que permita la conservación y difusión de centros históricos y culturales. Existen disímiles mecanismos para proteger el patrimonio cultural, entre ellos se encuentra la difusión de su existencia a toda la comunidad, el conocimiento y la comprensión del mismo. Esta difusión es la forma más efectiva para que las personas comprendan que es parte de su historia y que a partir de él se forja el desarrollo y la identidad nacional [1]. El modo de difundir ha cambiado con el de cursar de los años, tomando auge las nuevas Tecnologías de la Información y las Comunicaciones (TIC).

El área profesional de las Tecnologías de la Información y las Comunicaciones (TIC), precisa desarrollar el espíritu emprendedor y la iniciativa empresarial. El diseño de estrategias basadas en el uso de las Tecnologías de la Información y las Comunicaciones (TIC) evidencia y propicia el desarrollo económico a partir de la innovación tecnológica, como es el caso de los empresarios Jerry Yang creador de Yahoo, y Sergui Brin fundador de Google.

El carácter emprendedor de cada una de las instituciones que gestionan espacios públicos en en la actualidad se ha convertido en una necesidad para potenciar la relación de estas con las empresas, universidades, organizaciones no gubernamentales y movimientos sociales. Los gestores o especialistas garantizan este carácter a partir de su formación, es decir, debe tener nociones de iniciativa empresarial ya que es un profesional que puede contribuir de manera decisiva a crear condiciones para el desarrollo de las ciudades, contribuyendo al uso eficaz de objetos patrimoniales para lograr la transformación de procedimientos urbanos, necesarios en este siglo XXI.

Es por ello que se considera que la educación empresarial es el motor impulsor para inculcar la iniciativa emprendedora en los jóvenes cubanos, donde el talento florezca y permita llegar al entendimiento de que no todo el mundo puede convertirse en empresario. La innovación es el nombre del juego en los negocios, es difícil de lograr, porque no se trata solo de tener una buena idea. El capital intelectual y la gestión del conocimiento se convierten en los elementos claves para generar riquezas y obtener el éxito, estos conceptos forman el núcleo de una nueva teoría económica y de organización, que para lograrlas hay que ir más allá de la tecnología y el uso de la intuición.

Las TIC constituyen un ciberespacio en el cual se producen las interacciones humanas y se generan nuevas formas complejas en la mediación que se realiza en el proceso comunicacional. Ha tenido un gran impacto en el desarrollo del procesamiento y divulgación de la historia. Esta 
interdisciplinariedad se evidencia en los diversos medios de enseñanzas, creados para el tratamiento a la misma, algunos abarcan procesos generales que caracterizan la historia nacional y otros potencian las particularidades de esos procesos a partir del estudio y la investigación de la historia regional y local, como complemento indispensable en la reconstrucción de la Historia Patria. Pueden limar las barreras del conocimiento vigentes en los sitios históricos y mediante la interactividad, hacer que cada persona profundice en los contenidos hasta donde desee y acceder al patrimonio desde cualquier lugar con evidente ahorro económico. La necesidad de preservar y actuar en sitios históricos con extenso patrimonio cultural exige la utilización de tecnologías que permitan ubicar, documentar, describir y visualizar los sitios patrimoniales. En este ámbito juegan un papel importante las visitas virtuales, que son el modo de acercar y facilitar a los visitantes a un entorno o espacio concreto, con el fin de que lo mostrado sea fiel ejemplo del ambiente que recrean [2]. Es la vía más rápida, simple y económica de interacción, explorarlo y darlo a conocer a la sociedad. Una de las principales características que este brinda es la interactividad, la cual propone un diálogo entre usuarios y contenidos, que permita realizar exploraciones asociativas [3].

Teniendo en cuenta que las universidades deben orientar sus actividades académicas al desarrollo de la conciencia objetiva y crítica de los estudiantes, respecto a la realidad que vive la sociedad y en pos de contribuir a la preservación del patrimonio en la provincia Granma, se realizó un estudio de los principales sitios históricos, donde existen varios lugares con valor patrimonial entre los que se encuentran: Casa Natal de Carlos Manuel de Céspedes, Casa Natal de Celia Sánchez, Museo de Cera, Maqueta de la ciudad de Bayamo y la Catedral de Bayamo. A estos y otros sitios de la provincia y el país, solo se puede tener acceso mediante visitas presenciales, lo que limita la socialización de su patrimonio cultural. Es por ello que la presente investigación tiene como Objetivo general: potenciar el uso de las Tecnologías de la Información y las Comunicaciones en la difusión del patrimonio cultural, partiendo de una visión emprendedora.

El tema definido reviste gran importancia, por cuanto se pueden conocer mecanismos que se utilizan para divulgar y preservar el patrimonio cultural de la provincia Granma y otros sitios relevantes de Cuba. Además muestra cómo las universidades desde su enfoque académico contribuyen al desarrollo socioeconómico de un territorio y que para lograr un equilibrio entre tecnología y mercado es necesario conocer las necesidades de los clientes y a los competidores, y así asegurarse de que los recursos destinados al desarrollo y lanzamiento de un producto o servicio sean los adecuados. Esta es La clave del éxito empresarial. Los empresarios en el área de las TIC operan de forma privilegiada ya que tienen el conocimiento, la invención y la innovación tecnológica.

\section{REVISIÓN BIBLIOGRÁFICA}

\subsection{El emprendimiento empresarial}

El emprendimiento empresarial se podría definir como la iniciativa de un individuo para desarrollar un proyecto de negocios o una idea en particular que genere ingresos, es decir, crear una microempresa. Jeffrey A. Timmons, profesor de enfoque empresarial y autor de "The Enterpreneural Mind" brinda su propia definición: "Significa tomar acciones humanas, creativas para construir algo de valor a partir de prácticamente nada. Es la búsqueda insistente de la 
oportunidad independientemente de los recursos disponibles o de la carencia de éstos. Requiere una visión y la pasión y el compromiso para guiar a otros en la persecución de dicha visión. También requiere la disposición de tomar riesgos calculados..." [4].

Al emprendimiento empresarial se le había restado importancia, pero actualmente se le ve como una posibilidad de alcanzar al progreso en las naciones en vía de desarrollo. Entre las ventajas que tiene el emprendimiento empresarial, encontramos: la posibilidad que tiene el individuo de manejar su propio tiempo y ser su propio jefe, tomar decisiones autónomas, ingresos crecientes, además de que genera empleo.

\section{El emprendedor debe ser:}

- Audaz: para controlar su medio, estar dispuesto a correr riesgos y ser capaz de afrontar las situaciones que se le presente.

- Tenaz: para levantarse una y mil veces, lograr sus fines, tener una firme convicción y hacer su segundo y tercer esfuerzo si es necesario.

- Responsable: para no culpara a los demás, usar excusas y aceptar sus errores.

- Apasionado: para no desanimarse nunca, ver siempre el lado bueno de las cosas y aprender de las derrotas.

\section{El emprendedor debe tener:}

- Confianza: para creer mucho en sí mismo, sentirse capaz de lograr todas las cosas y para que nada ni nadie lo derrumbe.

- Iniciativa: para saber que toda la organización le concierne, para que todas sus contribuciones sean valiosas y para no esperar a los demás.

- Voluntad: para seguir adelante, ser capaz de organizar su vida, ser cumplido y autodisciplinado.

Los principios por los cuales se regirá toda actividad de emprendimientos son:

- Formación integral en aspectos y valores como desarrollo del ser humano y su comunidad, autoestima, solidaridad y desarrollo del gusto por la innovación y el estímulo a la investigación y aprendizaje permanente. Fortalecimiento de procesos de trabajo asociativo y en equipo.

- Reconocimientos de la ciencia, el derecho y la responsabilidad del desarrollo de las personas como individuos y como integrantes de cada comunidad. Apoyo desde la perspectiva social, cultural, ambiental y regional.

\subsection{Las TIC en la difusión del patrimonio}

La difusión es una de las estrategias fundamentales para dar a conocer y hacer accesibles los valores patrimoniales. El empleo de estos bienes posee gran valor identitario e histórico para nuestro país.

Las nuevas tecnologías facilitan en gran medida la difusión del patrimonio cultural de numerosos lugares en el mundo. En la actualidad se realizan documentales, películas, artículos, etc., donde se aproxima a las personas a los lugares y objetos de valor histórico. En este sentido, la web ha desempeñado un papel fundamental al permitir el acceso a esta información. Los 
soportes informáticos dan lugar a nuevas formas comunicativas (teletexto, videotexto, hipertexto) que se integran en lo que se denomina "sistemas multimedia: "dispositivos o conjunto de dispositivos que permiten reproducir simultáneamente textos, dibujos y diagramas, fotografías, sonidos y secuencias audiovisuales y que se caracterizan por su capacidad interactiva. Tanto los programas multimedia como el Internet tienen carácter de hipermedia: la información se organiza y se presenta de una forma no lineal" [5].

Estas tecnologías en el ámbito del patrimonio cultural representan actualmente una novedosa y eficiente herramienta para su conocimiento y puesta en valor, lo que ha llevado al desarrollo de importantes proyectos y experiencias, con el objetivo de potenciar la difusión del objeto cultural. Las TIC permiten hacer más amigables los bienes y los servicios culturales y patrimoniales, así como extender estos hacia el consumo de públicos más amplios, que por cuestiones económicas o territoriales no pueden consumir, o por el contrario permiten abarrotar de públicos especializados o no, a las ofertas de las diferentes instituciones. La realidad virtual, las aplicaciones para la telefonía móvil y los portales web han aportado mucho en la promoción del patrimonio de la provincia Granma y del país en general.

\subsubsection{La realidad virtual en la difusión del patrimonio}

La Realidad Virtual (RV) es una aplicación de la tecnología computacional, cuyo objetivo es el de generar representaciones visuales que simulan mundos reales o ficticios. Debe lograr que el usuario tenga la sensación de estar presente en el mundo virtual [6].

Las visitas virtuales son una vía fácil, divertida e interactiva de ver un espacio en todas las direcciones con solo mover el mouse por medio de las fotografías panorámicas y permitir observar el espacio fotografiado en pantalla completa como si el visitante estuviese en el lugar.

Una vista panorámica 360 es una visión completa de un espacio. El usuario puede sentirse como si estuviera de pie dentro de un espacio y a continuación puede controlar su movimiento dentro del área, buscando por encima de ellos, por debajo y a su alrededor. Cada vista panorámica 360 se compone de una serie de fotografías 'unidas' mediante un software específico. Hoy, disímiles sectores están interesados en los Recorridos Virtuales como los restaurantes, museos, y todos aquellos que se benefician al mostrar su espacio para salvar tiempo y distancia. Existen varias técnicas para la representación de imágenes panorámicas en los recorridos virtuales, entre ellas: visualización de imágenes panorámicas planas, cúbicas, esféricas y cilíndricas.

El campo del desarrollo de aplicaciones para equipos móviles es relativamente nuevo. Por lo que no existe un amplio desarrollo de las mismas. Los paseos virtuales para dispositivos móviles logran cada vez más impacto por la facilidad de acceder a disímiles sitios patrimoniales sin la necesidad de estar sentado en una computadora.

\subsubsection{Los Sistemas de Información Geográfica para la difusión del patrimonio}

Los Sistemas de Información Geográfica (SIG), como se conocen en el mundo, son herramientas que proporcionan diversos servicios, una vez que estos cuenten con la información requerida para el procesamiento de los datos. Estos sistemas permiten capturar, almacenar, manipular y analizar datos de objetos del mundo real que tienen un componente geoespacial de una forma versátil y fácil [7]. 
La preservación del patrimonio también obtiene sus beneficios de estas aplicaciones a partir de su difusión, ya que en este caso ubica al usuario geográficamente permitiéndole saber dónde puede encontrar el lugar que desea conocer o visitar, e incluso puede darle la opción de hacer el recorrido virtual desde la propia aplicación.

\subsection{Portales Web}

Los sistemas de gestión de contenidos provienen del término en inglés Content Management (CM), son una expresión de reciente aparición aunque no sin cierta ambigüedad. Se asocia a un nuevo método para el diseño y desarrollo de portales Web que conlleva a:

- La inclusión de elementos digitales de diferentes tipos (textuales, gráficos y sonoros).

- El desarrollo de forma cooperativa y descentralizada.

- El paso de un modelo estático a otro mucho más dinámico.

- La reutilización de los contenidos.

Este concepto se asocia también con los nuevos enfoques de la Intranet, donde el mayor peso recae en los aspectos relacionados con la identificación de recursos de información internos y externos, su valoración, gestión y tratamiento eficiente. A esto se le une, la necesidad de utilizar tecnologías de la información y sistemas informáticos para el almacenamiento y distribución de información de naturaleza textual [8].

Como todo sistema Web, los portales se basan en principios como: diseño gráfico, navegabilidad, posicionamiento Web, intensidad en la red, concurrencia, carga de usuarios, desempeño ante las peticiones de los usuarios, disponibilidad, seguridad, etc. No obstante los portales se caracterizan por no contener ningún proceso de gestión, sus prioridades son la identificación, descripción, clasificación y ubicación de los servicios y contenidos a publicar [8].

Los tres pilares fundamentales de un Portal para atraer la atención del usuario y son:

- Información (Buscadores, directorios, noticias, catálogos y servicios)

- Participación (E-mail, foros, chat)

- Comodidad (brindar la mayor cantidad de información en un solo espacio y tenerlo todo a mano)

Para obtener un producto de software es necesario hacer uso de herramientas y técnicas que permiten lograr un resultado que satisfaga las necesidades de los usuarios finales y además enfocarlos desde visión empresarial para que tenga una oportunidad en el mercado. Es por ello que a continuación se describen una serie de herramientas y tecnologías que permiten difundir con un espíritu empresarial el patrimonio cultural.

\section{HERRAMIENTAS PARA EL DESARROLLO DE SOLUCIONES INFORMÁTICAS}

Las herramientas de desarrollo de software (HDS) han desempeñado un importante papel en el desarrollo de aplicaciones. Como consecuencia del avance tecnológico estas han experimentado también continuos cambios. Las Herramientas de Ayuda al Desarrollo de Sistemas de Información, surgieron para intentar dar solución a los problemas inherentes a los proyectos de 
generación de aplicaciones informáticas: plazos y presupuestos incumplidos, insatisfacción del usuario, escasa productividad y baja calidad de los desarrollos.

\subsection{Herramientas utilizadas para el desarrollo de recorridos virtuales}

Para el modelado de elementos virtuales existen herramientas de diseño, que constituyen un componente fundamental para la creación de los objetos 3D de forma tal que los mismos tengan una visualización con alto grado de realismo. Algunas de estas herramientas de modelado bajo licencias libres son:

K-3D: Es un programa libre para modelación y animación tridimensional. Cuenta con plugins para aumentar su potencia de procesamiento y hacerlo más versátil. Se destaca principalmente en el modelado con polígonos y cuenta con una completa documentación en línea [9].

Art of Illusion: es un programa de código libre dedicado a la modelación y el renderizado tridimensional. Se destaca por su interfaz con división por superficies, animación basada en wireframes y el procesamiento de texturas y materiales [9].

Blender: es unaherramienta multiplataforma dedicada especialmente al modelado, animación y creación de gráficos tridimensionales. Es compatible con todas las versiones de Windows, Mac OS X, GNU/Linux, Solaris, FreeBSD e IRIX. Tiene una muy peculiar interfaz gráfica de usuario, pues no se basa en el sistema clásico de ventanas; pero tiene a su vez ventajas importantes sobre estas, como la configuración personalizada de la distribución de los menús y vistas de cámara [10].

\subsubsection{Herramienta de edición de imágenes}

Gimp: es un programa de manipulación de imágenes de GNU. Permite el tratado de imagen en capas, para poder modificar cada objeto en forma totalmente independiente a las demás. GIMP lee y escribe la mayoría de los formatos de ficheros gráficos, entre ellos; JPG, GIF, PNG, PCX, TIFF, los de Photoshop y posee su propio formato de almacenamiento: xcf.

\subsubsection{Tecnologías}

Uno de los nuevos estándares de la Web3D es WebGL (Web-basedGraphics Library).Es un estándar web multiplataforma para una API (ApplicationProgramming Interface) de gráficos 3D de bajo nivel basado en OpenGL ES 2.0 y expuesto a través del elemento canvas de HTML5 como interfaces DOM (DocumentObjectModel). WebGL es una nueva tecnología potente para la visualización de gráficos 3D en la web.

\subsubsection{Motores gráficos}

Un Motor gráfico es el componente principal de software de una aplicación interactiva, que se ejecuta en tiempo real. Su uso simplifica el desarrollo de la aplicación y a menudo permite que la aplicación pueda verse en múltiples plataformas, tales como consolas de videojuegos y sistemas operativos de Mac OS, GNU/Linux y Microsoft Windows. La abstracción del hardware es una de las principales ventajas que posee el Motor. 
Away3D: es un motor 3D en tiempo real para Flash en ActionScript 3.0. Es de código abierto bajo la licencia Apache 2.0. Cuenta con más de veinticinco primitivas útiles y una sólida selección de tipos de materiales que fácilmente pueden extenderse. Sólida API de ActionScript que se encuentra ahora en la cuarta iteración. Versión 4.0 o superior. Incorpora materiales como: el color, mapa de bits, contorno, plano, video, fresnel, vidrio, Lambert, la dispersión de la superficie, los mapas de sombra / luz y otros más. Contiene varios tipos de cámara, tales como: libre, objetivo y luces tales como: punto, ambiente, dirección.

Se considera haya sido la mejor opción para el desarrollo de los recorridos virtuales desarrollados.

3.2 Lenguajes, herramientas y tecnologías utilizadas en el desarrollo de Sistemas de Información Geográfica

\subsubsection{Marco de trabajo}

Cocoon 2: separa claramente el contenido de la presentación y de la lógica, es de código abierto (Licencia Apache), permite modificar el comportamiento de la aplicación sin conocer el lenguaje en el que está implementado [11].

Ruby onRails: facilita una alta productividad para desarrollar aplicaciones de tipo Crear, Leer, Actualizar y Borrar, en inglés Create, Read, Update and Delete (CRUD). No necesita configuración, tiene una gran aceptación en la comunidad de desarrolladores .

Django: es un framework web de código abierto, escrito en Python, que cumple en cierta medida el paradigma del Modelo-Vista-Controlador. La meta fundamental de Django es facilitar la creación de sitios web complejos. Soporta varias bases de datos como MySQL, SQLite, Postgres y MS-SQL [12].

Al analizar algunas características de los framework antes mencionados, se considera que GeoDjango se especializa en la desarrollo de aplicaciones web basadas en ubicaciones geográficas. Cocoon 2 consume demasiada memoria y Ruby onRails posee problemas de escalabilidad 4, rendimiento y en el encoding UTF-8.

\subsubsection{Lenguaje de programación}

Python posee una licencia de código abierto denominada fundación para el software de licencia Phyton, del inglés Python Software FoundationLicense (PSFL), la cual es compatible con Licencia Pública General de GNU. Su sintaxis visual es muy clara, pues posee una notación identada, permitiendo a los programadores adoptar las mismas notaciones y que los programas tengan un aspecto muy similar.

\subsubsection{Sistema Gestor de Base de datos}

Dentro de los SGBD más utilizados se encuentran:

MySQL: es relacional y multiusuario. Entre sus ventajas se destacan la velocidad al realizar las operaciones, lo que le hace uno de los gestores con mejor rendimiento. Bajo costo en requerimientos para la elaboración de bases de datos. Puede ser ejecutado en una máquina con 
escasos recursos sin ningún problema. Facilidad de configuración e instalación y soporta gran variedad de sistemas operativos. [13]

SQLite3 tiene una pequeña memoria y una única biblioteca necesaria para acceder a bases de datos. Dentro sus ventajas se encuentran: cero configuraciones, simple y sencillo, multiplataforma. Es la base de datos más compacta. Permite que la base de datos se ejecute rápidamente pues existe menos información que mover desde y hacia el disco [14].

PostgreSQL es un potente motor de bases de datos relacional orientada a objetos. Entre sus principales ventajas se encuentran: instalación ilimitada, ahorros considerables en costos de operación, estabilidad, confiabilidad, extensibilidad y multiplataforma. Es diseñado para ambientes de alto volumen de datos. Posee herramientas gráficas de diseño y administración de bases de datos [13].

Al realizar un análisis de los SGBD antes mencionados se escoge PostgreSQL. MySQL a pesar de tener licencia libre, fue comprado por Oracle la cual es una empresa privativa, no asegurándose el futuro de este. Por otra parte, SQLite3 solo trabaja en el mismo disco de la computadora, no pudiéndose montar una base de datos como servidor hacia otras máquinas.

\subsubsection{Servidores de mapas}

Los servidores de mapas más usados son:

MapServer: entre las características que más se destacan están los múltiples lenguajes de scripting 6 que soporta como PHP, Python, Perl, Ruby, Java, C\# y la ejecución multiplataforma Linux, Windows, Mac OS X, Solaris, etc. Admite múltiples formatos de datos vectoriales como ESRI shapfiles, PostGIS, ESRI ArcSDE, Oracle Spatial, MySQL y otros a través de OGR y formatos ráster como TIFF/GeoTIFF, EPPL7, y otros a través de GDAL.

GeoServer es un servidor de software de código abierto escrito en Java que permite a los usuarios compartir y editar los datos geoespaciales. Es enteramente compatible con las especificaciones WMS, WCS y WFS. Dentro de sus principales características se encuentran: fácil utilización a través de la herramienta de administración vía web. No es necesario entrar en archivos de configuración grandes y complicados. Posee un soporte amplio de formatos de entrada Shapefile,

ArcGIS ofrece las siguientes ventajas: menor costo de propiedad a través del manejo centralizado, es enfocado en aplicaciones SIG, que pueden escalar para apoyar a muchos usuarios. Acceso al SIG a partir un navegador. ArcGIS Server provee la base geoespacial para una arquitectura orientada al servicio.

\subsubsection{Clientes ligeros}

AppForMap es distribuido bajo licencia GNU GPL v.2. Utiliza especificación de características simple del inglés Simple Feature Specification (SFS) para consultar y modificar bases de datos PostgreSQL/PostGIS. Utiliza PHP/MapScript para funcionar como cliente de MapServer. Se apoya en OpenLayers para el renderizado. 
GeoExt es distribuido bajo licencia BSD. Está basado en OpenLayers. Busca dar al usuario un SIG de controles avanzados en internet. Entre los servicios que soporta se encuentran: WFS y WFST.

OpenLayers el mismo tiene como licencia BSD. Es una librería JavaScript puro para la visualización de losdatos del mapa en la mayoría de los navegadores modernos, independiente de los servidores de mapas. Utiliza una interfaz de programación de aplicaciones de JavaScript para la construcción de aplicaciones web geográficas. Soporta re-proyección y funcionalidades básicas de edición en línea. Ofrece un interfaz de usuario simplificado que soporta servicios WMS y WFS. Las características por las que se destacó OpenLayers en su difusión en la comunidad es la simplicidad de uso.

\subsection{Herramientas para el desarrollo de portales web}

Para el desarrollo y mantenimiento de un portal web se utiliza generalmente un Sistema Gestor de Contenido (SGC) (CMS siglas en inglés de Content Management System) [8].

\subsubsection{Sistema Gestor de Contenido Drupal}

Drupal es un sistema de gestión de contenido modular y muy configurable. Es un programa de código abierto, con licencia GNU/GPL, escrito en el lenguaje de programación PHP. Es multiplataforma y dispone de gran cantidad de módulos y temas que le proporcionan características tales como personalización, flexibilidad y adaptabilidad. [15]

En el mundo se han desarrollado muchas aplicaciones importantes con este CMS, entre los que se encuentran: el sitio web del sistema operativo Ubuntu, el Portal Yahoo research, el Portal de la Universidad de Harvard (Gazette), el sitio de las Tecnologías NOKIA. En Cuba también ha tenido impacto, ya que existen varias instituciones que presentan su sistema desarrollado en Drupal, de los que se mencionan: el Portal de la Televisión de Granma, el Portal del Periódico La Demajagua y el Portal de la Cultura Matancera.

\subsubsection{Lenguajes de programación}

PHP: es un lenguaje interpretado de propósito general ampliamente usado y que está diseñado especialmente para desarrollo web y puede ser incrustado dentro del código HTML (siglas de HyperTextMarkupLanguage) en español lenguaje de marcado de hipertexto [16].

JavaScript: es un lenguaje de programación del lado del cliente, porque es el navegador el que soporta la carga de procesamiento. Gracias a su compatibilidad con la mayoría de los navegadores modernos, es uno de los lenguajes de programación del lado del cliente más utilizado [16].

XHTML: es el lenguaje de marcado pensado para sustituir a HTML como estándar para las páginas web. Es la versión XML 7 de HTML, por lo que tiene, básicamente, las mismas funcionalidades, pero cumple las especificaciones, más estrictas, de XML [16]. 


\section{RESULTADOS}

Con el objetivo de utilizar el conocimiento en función del desarrollo social de la región y el país, en la Facultad de Ciencias Informáticas de la Universidad de Granma se desarrollaron varias soluciones informáticas para la difusión del patrimonio, empleando algunas de estas tecnologías y herramientas.

\section{A continuación se describen algunas de las aplicaciones desarrolladas en función de la difusión del patrimonio cultural en el país:}

Paseo virtual a la Casa Natal de Carlos Manuel de Céspedes: En las salas del paseo virtual existen vínculos que permiten visitar las salas adyacentes y visualizar los principales objetos que allí se encuentran, para esto se utilizan flechas que indican la dirección lógica de desplazamiento; para los vínculos a objetos se utilizan áreas transparentes. El mapa del museo, además de permitir el acceso a cada sala, indica en cada momento la ubicación del visitante virtual. A través del visor panorámico cada una de las salas del museo puede ser recorrida virtualmente, de forma automática o libre. Para los recorridos automáticos se cuenta con controles que permiten la navegación horizontal en ambos sentidos y para detener la animación. El otro control oculta o muestra los vínculos en dependencia de si son visibles o no; si se ocultan los vínculos se puede apreciar mejor la panorámica. La navegación libre se garantiza por medio de la interacción del mouse con la panorámica.

Paseo Virtual al Museo de Cera: tiene las mismas funcionalidades que el anterior, ya sea para el recorrido de las salas, para la visualización de la información acerca de las figuras que se encuentran en ésta, así como para permitir el acceso a cada sala mediante el mapa del museo y a través del visor panorámico. Además brinda la posibilidad de utilizar los cursores del teclado para ambos recorridos, las que permiten mover la imagen a la derecha, izquierda, arriba, abajo y para detener el recorrido se utiliza la tecla espacio. También se puede utilizar el mouse para realizar el recorrido.

Museo Virtual Casa Natal Celia Sánchez Manduley: en esta ocasión, la vista, "Recorrido Virtual" está dividida en dos secciones: el visor panorámico (en la parte izquierda de la imagen) y el plano de situación. En la parte superior del visor se encuentra el nombre de la sala y un vínculo que permite visualizar una breve descripción de la misma. El área principal del visor está dedicada a la visualización de la imagen panorámica de la sala que se visita. Por medio de la interacción con el mouse se garantiza el recorrido libre y por el teclado se logra un desplazamiento continuo y uniforme por la sala. A través del visor también se pueden ampliar los principales objetos de la sala que se visita, permitiendo visualizar una breve descripción del mismo y visitar las salas adyacentes. En el plano de situación se muestra la distribución física de las salas en el museo, se indica la ubicación del visitante y el área que está viendo en cada momento.

Museo Virtual Ñico López: cuenta con una vista "Panorama" que está dividida en dos secciones: la principal es el área donde se visualizan las panorámicas de las salas correspondientes, en esta se encuentra el vínculo que permite acceder a la información de dicha sala; una segunda contiene un mapa del museo que permite de forma rápida acceder a cada una de las salas manteniendo informado del lugar visitado. En el visor panorámico las salas pueden ser recorridas virtualmente, de forma libre o guiados. Los recorridos guiados se realizan a través de la información 
que es generada por el sonido correspondiente a dicha sala. El recorrido libre es por medio de la interacción del teclado, los cursores dan la dirección que puedes recorrer y la barra espaciadora detiene la panorámica.

Recorrido Virtual por el Patrimonio de Manzanillo: el Recorrido Virtual por el patrimonio de Manzanillo, está constituido por un sitio web mediante el cual se puede observar algunos de los inmuebles más importantes de la ciudad de Manzanillo así como su historia, valor arquitectónico y cultural. El sitio cuenta con dos visores de imágenes panorámicas salado Player (visor flash) y PIViewer (visor HTML5).

Recorrido Virtual del Museo Provincial: el recorrido se realiza mediante una aplicación web que brinda información relevante acerca del museo, compuesta por un paseo virtual con imágenes panorámicas. Se visualiza información que el usuario debe conocer, de tal manera que le permita realizar un recorrido por cada una de las salas expositivas, donde se muestra una pequeña descripción de las piezas museables más destacadas con las que cuenta la institución. Este recorrido virtual fue un complemento a la información, el mismo contribuyó a conservar y divulgar el patrimonio tangible e intangible que atesora la institución y conocer sobre la historia de dicho museo. El recorrido virtual con imágenes panorámicas se garantiza con el uso de un visor panorámico y un plano de posición interactivo.

Sistema de información geográfica Tourdroid: aplicación orientada a dispositivos smartphones con SO Android. El sistema permite el acceso por parte de los usuarios de forma inmediata a la información de las instalaciones patrimoniales y culturales de mayor interés de la ciudad de Bayamo, garantiza que los usuarios perciban el aspecto visual real de las instalaciones promocionadas en el SIG. Brinda la interacción con recorridos virtuales, de manera que el usuario se sumerja en un ambiente informático que simule de manera virtual el entorno real de cada institución patrimonial. Aunque inicialmente fue concebido para la ciudad de Bayamo, la herramienta posee una arquitectura adaptable para estandarizarla a otros entornos; lo cual se sustenta en que solo es necesario la modificación de la información contenida en su base de datos.

Paseo Virtual 360 grados para Teléfonos Móviles de la Casa Natal de Carlos M. de Céspedes: con la realización de este proyecto se obtuvo un paseo virtual 360 grados de la Casa Natal de Carlos M. de Céspedes. Dicha aplicación puede instalarse y verse en los teléfonos móviles (celulares) que puedan ejecutar aplicaciones Java.

Portal del Centro Provincial de la Música "Sindo Garay" de Granma: la solución visualiza los dossiers de las unidades artísticas representadas por la entidad, discografías de las agrupaciones, las personalidades de la música en la provincia, así como un catálogo del centro y noticias relacionadas con el quehacer artístico en Granma. Además, brinda servicios de búsquedas en el portal y muestra un calendario de eventos que permite consultar los eventos de una fecha determinada. También permite la publicación de encuestas en la que los usuarios autenticados puedan participar.

Portal Web del Fondo Cubano de Bienes Culturales de la provincia Granma: es un portal web desarrollado con el objetivo de perfeccionar la promoción de las obras de arte y los servicios que ofrece el FCBC de la provincia Granma. El sistema permite gestionar todos los datos referentes a los artistas y sus obras, así como generar una serie de catálogos personalizados. 
Portal Web para la publicación y difusión de la vida y obra de Carlos Puebla: en un portal web que brinda la posibilidad de acceder a la vida y obra artística de Carlos Puebla, así como descargar cualquier material discográfico publicado en el mismo.

Portal Web sobre la historia y la cultura culinaria en Granma: el arte culinario es una manifestación que forma parte de la supervivencia humana, además de crear una entidad de expresión distintiva. "Las comidas se convierten en un hecho patrimonial de gran importancia, la dimensionan dentro de las comunidades, los pueblos y las naciones, incluso lo determinan socialmente. El sistema permite visualizar información acerca de los principales platos que distinguen a la provincia Granma.

Portal de la programación cultural en Granma: el Portal está destinado a divulgar y promover las diferentes acciones que se realizan para conservar el patrimonio avileño. La arquitectura de la información del mismo está en correspondencia con la organización y distribución de las diferentes oficinas, redes de monumentos y museos que lo conforman. Contiene gran cantidad de artículos e imágenes de los principales lugares y objetos de gran valor patrimonial. Muestra las efemérides del día y las enlaza con los artículos relacionados. Es el principal medio de divulgación de eventos relacionado con el patrimonio en la provincia de Ciego de Ávila.

Portal Casa Natal de José Martí: el producto es divido por temáticas sencillas ya que el mismo va dirigido principalmente a niños: Historia, Biografía, Ejercicios, Glosario y Poesías.

Estos productos son el resultado del trabajo de equipos interdisciplinarios donde intervienen especialistas de patrimonio, cultura e informática, propuestas consolidadas científicamente que invitan a la reflexión de quienes las consumen y al mismo tiempo contribuyen a difundir el patrimonio de la provincia Granma y otros lugares del país.

\section{CONCLUSIONES}

El uso de recursos tecnológicos unido al espíritu empresarial y emprendedor, origina nuevas experiencias y un nuevo rol del individuo en la sociedad actual, como miembro que interactúa y participa en la mejora del patrimonio cultural, divulgando su práctica y difundiendo su concepción de ente accesible y participativo. Todas estas cualidades hacen que el impacto y contribución social de las TIC en el patrimonio y demás instituciones culturales deba ser considerado como medio que revaloriza el papel del visitante a los sitios patrimoniales como principal trasmisor de su práctica y contenidos. Sin duda las oportunidades que ofrece el uso de las nuevas tecnologías deben modificar el patrón de comportamiento no solo de los interesados en conocer el patrimonio de un territorio sino también de los educadores, gestores e investigadores.

\section{REFERENCIAS}

1. Fujita, F. F. Patrimonio Cultural. Revista Arqueología. Boletín Andinas, n. 1, 2,3 Perú 2015.

2. Regil, L. Museos Virtuales: entornos para el arte y la interactividad. Revista Digital Universitaria, v. 7, n. 9, p. 4-10, septiembre 2006.

3. Regil, L. MUSEOS VIRTUALES: ENTORNOS PARA EL ARTE Y LAINTERACTIVIDAD. Revista UNAM, v.7, n.9, art.7, septiembre 2007. 
4. Bueno, J. E. El emprendimiento empresarial, un motor de desarrollo. Revista Secretos de prosperidad, enero 2009.

5. Rico, L. La difusión del patrimonio a través de las nuevas tecnologías. Nuevos entornos para la educación patrimonial Histórico-Artística. Universia. Bilioteca de recursos, diciembre 2013.

6. Larrea Martín, D., Flores, D. TICs y Difusión del Patrimonio Cultural. CDICI, Red universitaria de estudios de Informática, 2012.

7. Ramos, M. El uso de la tecnología geoespacial: un caso de aplicación. El colegio de Tlaxcala, edición 1, 2009.

8. Santana, W. Procesos de desarrollo de portales web. Revista Digital de las Tecnologías de I Información y las Comunicaciones, v. 12, n. 3, p. 42-45, septiembre-diciembre 2013.

9. Aplicaciones de modelado 3D. Herrameintas libres de diseño 3D, disponible en http://www.blender.org/featuresgallery/features

10. Instituto Nacional de Tecnologías y formación de Profesorado. Blender: 3D en la educación, disponible en http://www.ite.educacion.es/formacion/materiales/181/cd/m1/qu_hace_blender.html.

11. Zárrate, S. Apache Cocoon 2: Motivación, Introducción y Explicación, p. 3-5, agosto 2002.

12. Django. Django at a glance, publicado en https://docs.djangoproject.com/en/1.5/intro/ overview/

13. Pérez, A. A. Desarrollo de herramientas web de gestión docente, c.2, p. 12-15, diciembre 2007.

14. Martín, D. Sqlite el gestor de base de datos ágil y robusto. Empresa y economía, publicado en: http://www.empresayeconomia.es/aplicaciones-para-empresas/sqlite-el-motor-de-base-dedatos-agil-y-robusto.html

15. Rivero, J. M. Desarrollo de portales web con Drupal. Hipermedio, publicado en: http://www.hipermedio.com

16. Péres, D. Los diferentes lenguajes de programación web. Revista Maestros del Web, noviembre 2007. 